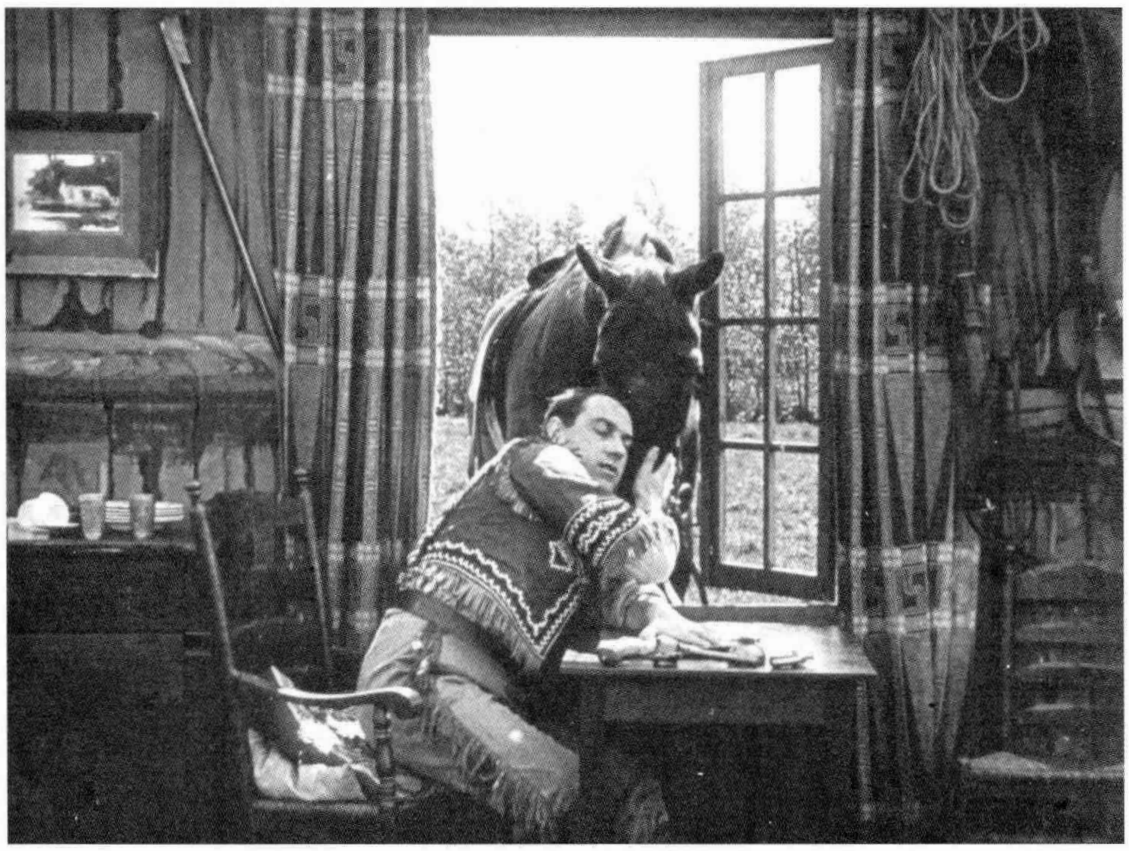




\section{Gerardo G. Sánchez Ruiz}

Ingeniero arquitecto y maestro en planificación (ESIA-IPN) y doctor en urbanismo (FA-UNAM). Profesor-investigador en la División de Ciencias y Artes para el Diseño de la Universidad Autónoma Metropolitana Azcapotzalco. Miembro del Sistema Nacional de Investigadores nivel I. Tiene cinco libros como autor, el último: Planificación y urbanismo de la revolución mexicana. Los sustentos de zna nueva modernidad en la ciudad de México, 1917-1940, UAM-Azcapotzalco/Asamblea Legislativa, México, 2002; cinco libros colectivos, el último como cootdinador: Planificación y urbanismo visionarios del arquitecto Carlos Contreras, UAM-Azcapotzalco/UNAM/UASLP, México, 2004. Ha publicado artículos en Excélsior, El Financiero y El Economista.

\section{Resumen}

En los años veinte del siglo pasado, un grupo de profesionales mexicanos apoyados en las ideas de planeación que en ese momento transformaban a las principales ciudades del mundo, generaron un cuerpo teórico, jurídico e instrumental, para sumarse a la atención de carencias de una sociedad que entre los ímpetus de la revolución aspiraba a progresar. Sin embargo, avanzados los años y en medio de contradicciones sociales, esas ideas y prácticas inherentes al concepto de planificación fueron desvinculadas del ámbito de ciudad, región y nación, reducidas al de mera apertura de calles y, no obstante, calificadas como urbanismo. La historia se sumó a esa minimización al no rescatar esas ideas o prejuiciarlas; es por ello el interés del artículo por reconstruir esa historia desde sus fuentes, y en esta parte, de las situaciones aprendidas por los profesionales mexicanos en el exterior.

\section{Palabras clave:}

Historia urbana, planificación, urbanización, modernidad, prejuicios, fuentes teóricas y prácticas.

\section{Abstract}

During the 1920s, on the basis of the planning ideas that were transforming the world's main cities, a group of Mexican professionals devised a theoretical, legislative and instrumental body to deal with the shortages of a society that was striving to progress in the wake of the revolution. Nevertheless, as the years went by and in the midst of social contradictions, these ideas and practices, grouped together under the concept of planning, were separated from the sphere of the city, region and nation, recluced to the mere opening up of streets and, notwithstanding, regarded as town planning. History contributed to this minimization by failing to recover these ideas or prejudging them. That is why the article seeks to reconstruct this history from its sources, and in this section, from the situations conceived of by Mexican professionals living abroad.

\section{Key words:}

Urban history, planning, urbanization, modernity, prejudices, theoretical and practical sources.

Fecha de recepción: marzo de 2005

Fecha de aceptación: junio de 2005 


\title{
La modernidad urbana en México. Fuentes teóricas y prácticas de la primera mitad del siglo $\mathrm{XX}^{*}$
}

\author{
Gerardo G. Sánchez Ruiz
}

$\mathrm{E}$ $n$ el pensamiento que desde mediados del siglo XIX buscó interpretar y atender la dinámica territorial del mundo, se gestaron conceptos que caracterizaron o buscaron resolver problemas en ciudades, regiones y naciones: urbanismo, Städtebau, civic art, civic improvement, improvement of towns and cities, site planning, city planning, town development, town planning, country planning, y, en el caso de México, planificación; conceptos que acompañados de acciones, atendieron aspiraciones de progreso en diversas partes del mundo en los siglos XIX y XX. Esos conceptos, como expresión de las sociedades que los generaron, se construyeron primero individualmente para atender problemas muy propios y casi sin participación estatal; para posteriormente caracterizar prácticas o tendencias de conjunto, con una amplia participación estatal y conformando movimientos internacionales.

En ese contexto, desde los años veinte del siglo pasado un grupo de profesionales mexicanos, apoyados en ideas traídas

* Este trabajo es una síntesis de una investigación que el autor desarrolla con título: Fuentes teóricas y prácticas en la planeación de ciudades mexicanas. La primera mitad del siglo XX, trabajo que continúa la línea trazada por el libro Planificación y urbanismo de la revolución mexicana (2002) también del autor. de Europa y Estados Unidos, generaron un cuerpo teórico, jurídico e instrumental con el que se sumaron a la atención de carencias de una sociedad producto de la revolución, que aspiraba a ingresar a una nueva modernidad. Sólo que avanzadas dos décadas y en medio de una modernidad que se tornaba desigual, ideas y prácticas fueron conducidas de una concepción ampliada del territorio con ámbitos de ciudades, regiones y naciones, y agrupadas con el concepto de planificación, a una perspectiva en extremo ligada a la simple apertura de calles y connotada como urbanismo.

Lamentablemente, la historia sobre cuestiones urbanas se sumó a esa minimización al historiar con prejuicios o no profundizar ante lo reflexionado y realizado. Casos de esto fueron por ejemplo, ligar el trabajo de esos profesionales a la inexistente influencia de Le Corbusier, o señalar que aquéllos no hacían planes sino planos. En esa dinámica, ideas y realizaciones de arquitectos como José Luis Cuevas Pietrasanta, Carlos Contreras Elizondo, Luis R. Ruiz, e ingenieros como Enrique E. Schulz, Modesto C. Rolland y Miguel Ángel de Quevedo, fueron confinadas a discusiones en revistas y periódicos o en archivos, con lo que se perdió gran parte cle lo ideado y construido, pero además, una continuidad en la disciplina que hubiera 
posibilitado mayores niveles de profesionalización y probablemente mejores resultados ante los problemas sufridos por las ciudades mexicanas. Dado ese panorama, el objetivo de este trabajo es escudriñar el contexto y pensamiento que envolvió la práctica de esos profesionales al colocar a la planificación entre los ímpetus transformadores de una sociedad que hizo su vida en el siglo XX.

Para cumplir con el objetivo se partió del artículo "Primeras hiladas para nuestro arte cívico" (1923), escrito por José Luis Cuevas Pietrasanta después de haber realizado un viaje a Bélgica en 1921. En este trabajo el autor recomienda a los arquitectos jóvenes de México un conjunto de textos para que se adentren en el arte cívico. También se consultaron la revista Planificación (1927-1934), que registra trabajos de los más influyentes planificadores de México y del extranjero; los libros The American Planner (1983) y The Genesis of Modern British Town Planning (1972), que exponen contextos y profesionales externos -y contrastan los autores recomendados por Cuevas-; y memorias de los congresos de International Housing and Toun Planning (IHTPC) impulsados a inicios del siglo XX por personas como Ebenezer Howard, $\mathrm{Pa}$ trick Geddes, Thomas Adams y Raymond

${ }^{1}$ Aquí se utilizará el concepto planificación como lo planteó Carlos Contreras al señalar: "El año pasado en Torreón apunté ideas preliminares sobre el significado de los términos ingleses PLANNING, a secas, y con los sustantivos site, city, regional, country, national, y de la traducción que había hecho yo desde 1921 y más tarde en 1924 cuando preparé un esquema para el trazo del camino de México a Puebla y empecé a darle forma a mi proyecto de Planificación Nacional, creando el barbarismo PLANIFICACIÓN, que a pesar de su humilde origen sigue creciendo normalmente." Contreras, Asociación, 1926, p. 590.
Unwin, y de los que el encuentro número XVI se realizó en México.

\section{SUPUESTOS DEL PROGRESO \\ Y LAS PROPUESTAS DE A'TENCIÓN PARA LAS CIUDADES}

De acuerdo con Françoise Choay (1969) y George R. Collins (1986), Idelfonso Cerdá, al impulsar arreglos para Barcelona, fue quien en su obra Teoría general de la urbanización (1867) acuñó el concepto de urbanismo, el cual fue rescatado e impulsado para caracterizar los trabajos en ciudades y regiones bajo la influencia de los Congresos Internacionales de Arquitectura Moderna (CIAM) iniciados en 1928; y de acuerdo con Frank Koester (1914), Reinhard Baumeister (1833-1917) generó en Alemania el concepto de planeación de ciudades (1876), con el que desde fines del siglo XIX se caracterizó a los trabajos realizados en Alemania, Inglaterra y Estados Unidos, y que influyó lo realizado en México entre los años veinte y cuarenta.

Esos conceptos buscaban interpretar situaciones y prácticas de un mundo que, como obra de una nueva modernidad, años más años menos, hảbía visto crecer a sus principales ciudades con los consecuentes cambios en estilos de vida; sólo que el supuesto progreso que se pretendía, se presentó entre condiciones de insalubridad, hacinamiento, inseguridad, contaminación, accidentes en calles, etc. De ahí que a lo largo del siglo xIx las preocupaciones y los estudios que medían y actuaban en relación con las ciudades, se ampliaran y persistieran. Al respecto, $\mathrm{Fe}-$ derico Engels en La situación de la clase abrera en Inglaterra (1845), al señalar algunas de las condiciones de Londres, Man- 
chester y Liverpool como efecto de ese andar de la modernidad, apuntaba:

El gran establecimiento industrial requiere muchos obreros, los que trabajan juntos en un edificio deben vivir juntos, forman ya una villa, aun cuando la fábrica es pequeña. Tienen necesidades, y para satisfacerlas, es necesaria otra gente; obreros, sastres, zapateros, panaderos, albañiles, carpinteros, son admitidos, pues, en la aldea. Los habitantes de ella, especialmente la joven generación, se habitúan al trabajo de la fábrica, se familiarizan con él, y si la primera fábrica no puede ocuparlos a todos, el salario desciende; en consecuencia, se establecen nuevas fábricas. $\mathrm{Y}$ así surge, del pequeño villorrio, una pequeña ciudad y de ésta una grande. Cuanto más grandes son las ciudades, mayores son las ventajas de la colonización. [...] se tiene un mercado, una bolsa, a la cual afluyen los compradores; se está en unión directa con los mercados que dan la materia prima o aceptan las mercaderías elaboradas. De ahí el maravilloso desenvolvimiento de las ciudades. $^{2}$

La diversificación de actividades como exigencia de la industrialización, incidió en una cierta desorganización y carencias en las ciudades, a los que correspondieron los consecuentes reclamos de salubridad, vivienda, educación, recreación, cultura, etc. De ahí que en "Las desventuras de New York" (1877), para justificar nuevos arreglos para esa ciudad, Frederick Law Olmsted -el padre de la arquitectura del paisaje en Norteamérica- decía que, cuando la comunidad neoyorkina en 1807 había adoptado un plan de calles perfilándose con ello como la gran metrópoli del

\footnotetext{
${ }^{2}$ Engels, Situación, 1984, pp. 51-52.
}

mundo, ésta no tenía gas, agua, sistemas de alcantarillado, y que "la basura de la casa a menudo era arrojada, con sus nutridas y sucias aguas en la calle frente a la puerta, para ser devorada por los puercos". 3

De igual modo, Olmsted señalaba que, debido a la dinámica con que se había extendido Nueva York, se había arrasado con praderas y flores, y que en esos años se estaban resintiendo enormes cambios en el desenvolvimiento del comercio, comunicaciones y estilos de la vida de sus habitantes; de ello se explican las inquietudes de Olmsted, quien pretendía reformular la manera de crecer de esa y otras urbes, proponiendo amplios espacios de áreas verdes.

Por supuesto, las críticas condiciones en que se desenvolvían las ciudades afectaban a todos sus habitantes, de ello se entiende que Engels, para el caso de Inglaterra, sostuviera que "las repetidas visitas del cólera, tifus, de la viruela y otras epidemias", habían "impuesto al burgués británico la urgente necesidad de sanear la ciudad, si él mismo no quería ser víctima, con su familia, de esas epidemias". ${ }^{4} \mathrm{De}$ ese modo, los efectos sobre los distintos grupos sociales -de acuerdo con su pertenencia social-y los requerimientos empresariales, obligaron a generar y aplicar variadas políticas para atenuar problemas.

La introducción de drenaje, la ampliación de calles, la pavimentación, la insistencia en áreas verdes, etc., fueron desplegándose primero como iniciativas aisladas $y$ de particulares para finalmente, a finales del siglo XIX y principios del XX, realizarse con una amplia participación de asociaciones y gobiernos. Era un hecho que las aspiraciones sociales y el desenvolvimiento

\footnotetext{
3 Olmsted, "Desventuras", 1997, pp. 44-45.

"Engels, Situación, 1984, p. 12.
} 
económico y territorial exigían mayor orden y atención a rubros que por su magnitud, carácter de su uso y lenta amortización, sólo instancias gubernamentales podían atender; de ahí que esas situaciones coadyuvaran para que el Estado liberal diera paso al Estado interventor, solidificándose de ese modo órganos planificadores.

En ese crecer se pasó de planos o esquemas que atendían sobre todo cuestiones físicas y estéticas, a documentos sustentados en cuestiones económicas, demográficas, estéticas, sanitarias, etc., ofreciendo nuevas perspectivas a la disciplina. Indefectiblemente en ese evolucionar fueron importantes los foros donde se confrontaban perspectivas teóricas y manejos técnicos, la difusión de las reflexiones a través de folletos y libros, la conformación de grupos interdisciplinarios, y desde luego, el interés empresarial en tanto la planeación brindaba la oportunidad de acrecentar ganancias.

Un parteaguas en el desenvolvimiento de la disciplina lo representó la remodelación que impulsó el barón Georges Haussmann para París (1853-1870) donde, en una condición de modernidad y de reinterpretación de los trazos de las ciudades barrocas no tan lejanas de la historia de Francia, se conjugaron seguridad, higiene, estética y funcionalidad. Por supuesto, la nueva imagen y la refuncionalización obtenida a partir de las grandes avenidas, impactaron a los parisinos a la vez que motivaron a gobiernos y a interesados en los problemas de otras ciudades, a intentar experiencias similares. ${ }^{5}$

${ }^{5}$ De ahí los trabajos de Eugène Henard (18491923) en Francia, Joseph Stuiben (1845-1936) en Alemania, Antonio Rovira y Trias (1816-1889) en España, Daniel Burnham (1846-1912) en Estados Unidos;
No obstante los avances, no todos los habitantes de los pueblos y ciudades recibían los beneficios de las acciones derivadas de la planeación, pues los beneficios se extendían de acuerdo con los recursos utilizados, las pertenencias sociales, el carácter de órganos planificadores y la perspectiva del Estado. Esa forma de atender a las ciudades y la manera en que surgían nuevos barrios y periferias pobres, fueron abordados por Federico Engels en su Contribución al problema de la vivienda (18721873), al referirse así respecto al Plan del barón Haussmann:

Entiendo aquí por Haussmann, no solamente la manera específica bonapartista del Haussmann parisino de trazar calles anchas, largas y rectas a través de los barrios obreros construidos estrechamente, $y[\ldots]$ transformar $\mathrm{Pa}$ rís en una ciudad de lujo. Entiendo por Haussmann la práctica generalizada de abrir brechas en barrios obreros, particularmente los situados en el centro de nuestras grandes ciudades, ya responda esto a una atención de salud pública o de embellecimiento o bien a una demanda de grandes locales de negocios en el centro, o bien a unas necesidades de comunicaciones, como ferrocartiles, calles, etc. El resultado es en todas partes el mismo, cualquiera que sea el motivo invocado: las callejuelas y los callejones sin salicla más escandalosos desaparecen y la burguesía se glorifica con un resultado tan grandioso; pero.... callejuelas y callejones sin salida reaparecen prontamente en otra parte, $y$ muy a menudo en lugares muy próximos. ${ }^{6}$

y el trazo de la avenida Reforma en la ciudad de México (1864) impulsado por el archiduque Pernando Maximiliano de Habsburgo, al ocurrir el segundo imperio.

${ }^{6}$ Engels, “Contribución", 1979, pp. 371-372. 
Aun así, los esfuerzos se sucedían adquiriendo mayores niveles tanto en la interpretación de los problemas como en las acciones; ejemplos de ello fueron el Primer Informe de la Comisión Real sobre Corporaciones Municipales de Inglaterra y Gales (1835), el Informe del Comité Selecto sobre la Salud de Ciudades (1840), el Primer Informe de la Comisión Real sobre el Estado de las Grandes Ciudades y Distritos Populosos (1844) y las actas de vivienda para obreros en particular la Housing and Town Planning Act de 1909, en el caso de Gran Bretaña; ${ }^{7}$ el Plan para la Ciudad de Nueva York (1871), la apertura de la Escuela de Arquitectura del Paisaje en la Univèrsidad de Harvard (1900), el Reporte para el Comité del Senado para el Distrito de Columbia (1902) y el Plan de Chicago de Daniel H. Burnham y Edward H. Bennett (1906-1908) en el caso de Estados Unidos. Era un hecho que el interés por los territorios y el mayor desarrollo de las disciplinas interesadas en los fenómenos territoriales, tomaban un carácter más estructurado.

Es en ese panorama de preocupaciones, de observar, reflexionar y de plantear proyectos y acciones, que profesionales mexicanos adoptaron algunas de esas guías pretendiendo atender los problemas que la anhelada modernidad les exigía. Concluidas las batallas revolucionarias, el país y sus principales ciudades afrontaban problemas en la producción y distribución de bienes, movimientos poblacionales, salud, habitación, educación, recreación, etc.; urgía reconstruir, pero a la vez atender las aspiraciones de una nueva sociedad que

\footnotetext{
${ }^{7}$ Esta acta se convertiría en una de las guías más influyentes en los procesos de planeación en ciudades británicas y en otros países.
}

exigía desde zonas especiales para actividades industriales y de comercio, hasta la de educarse en una escuela.

De acuerdo con el Anuario Estadístico de los Estados Unidos Mexicanos (1948), México tenía, en 1921, 14334780 habitantes y 26 localidades con más de 20000 habitantes de las cuales nueve tenían más de $50000 .^{8}$ Reflexionando esos datos, más el hecho de que Inglaterra contara con una norma que establecía que, a partir de 1923 , todos los condados que administraran ciudades con más de 20000 habitantes debían preparar planes, ${ }^{9}$ en México para 1921 ya tenían que considerarse planes para 26 ciudades. Por supuesto, las condiciones de México eran diferentes pero sí se exigía la atención de sus principales enclaves urbanos ya fuera por el abrumador crecimiento de los fraccionamientos, la falta de equipamiento y servicios o la necesidad de hacer más fluidas las actividades económicas.

Un rubro muy demandante de acciones era el de la salud, ello era evidente si se considera que entre 1933 y 1937 el promedio anual de defunciones en las principales ciudades se desglosaba así: en la ciudad de México las principales causas de las 29942 había sido: neumonía en 6256 casos, diarrea y enteritis en 5926 , y bronquitis en 791; en Guadalajara, de las 6466 defunciones, 1817 se debían a diarrea y enteritis, 865 a neumonía, y 107 a sarampión; en Monterrey las principales causas de las 3982 defunciones eran dia-

${ }^{8}$ Estas últimas eran: Torreón con 50902 , León 53 639, Veracruz 54 225, San Luis Potosí 57 353, Mérida 79 225, Monterrey 88 479, Puebla 95 535, Guadalajara 143376 y la ciudad de México 615377. Anuario, 1948.

${ }^{9}$ Purdom, Introductory, 1921, p. 9. 
rrea y enteritis en 1090 casos, neumonía en 438, y paludismo en 113; en Puebla, de las 3420 defunciones, 858 se debían a diarrea y enteritis, 766 a neumonía y 56 a bronquitis. ${ }^{10}$

Por supuesto, buena parte de las muertes era efecto de una combinación de factores que tenían que ver con las condiciones de las ciudades, y una buena parte de ellas se relacionaba con la carencia de hospitales, el hacinamiento por falta de vivienda, la insalubridad por la falta de pavimentos, drenaje y agua potable, etc.; sin dudarlo, las particularidades de muchos de esos aspectos aunados a los existentes en otros ámbitos, exigían la intervención de gobierno y de profesionales que se formaban en el campo de la planificación.

\section{AUTORES E IDEAS QUE IMPULSARON EL TRABAJO DE LOS PROFESIONALES MEXICANOS}

Como ya se apuntó, un buen número de los autores que a principios del siglo Xx se leían, fue registrado por el arquitecto José Luis Cuevas Pietrasanta en un artículo que escribió como consecuencia de una visita a la ciudad de Brujas en 1921; en el escrito, Cuevas mostraba su entusiasmo por las propuestas que, para reconstruir sus ciudades, los arquitectos belgas mostraban en una exposición. Ese entusiasmo, aunado a su asistencia a conferencias relacionadas con la planeación de ciudades, lo llevó a escribir:

Y fue entonces cuando se abrió ante mis ojos una perspectiva inmensa, que se dilataba

${ }^{10}$ Mortalidad, s.a. más y más a medida que aprenclía después, en los núcleos especialistas sobre Arte Cívico, instituidos para ese estudio en muchas otras de las principales ciudades, lo que en pro de ese esfuerzo se había hecho, las ideas que privaban para proporcionar albergue mejor a los obreros y trabajadores; y sobre todo lo que se había alcanzado en la replanificación de ciudades para mejorar sus condiciones propias y dotarlas de más altas y mejores bellezas. ${ }^{11}$

El artículo de Cuevas incluía 71 libros y once revistas especializadas. De entre los primeros sobresalen: Das Deutsche Miethaus (1909) de F. Bruckman A. G. München; Civic Art (1911) de Thomas H. Mawson; Ancient Town Planning (1913) de F. Haverfield; The Garden City (1913) de C. B. Purdom; Practical Housing (1910) y Practical Town Planning (1914) de J. S. Nettlefold; Cities in Evolution (1915) de Patrick Geddes; City Planning with Special Reference to de Planning of Streets and Lots (1916) de Charles Mulford Robinson; Plan of Minneapolis (1917) de Edward H. Bennett; Het Moderne Landbuis in Nederland (1917) de J. H. W. Leliman; L' Art de Bâtir les Villes (1918) de Camillo Sitte; Local Development Law (1919) de Harold Chaloner Dowdall; New Ideals in the Planning of Cities, Towns and Villages (1919) de John Nolen; The Planning of the Modern City (1916) de Nelson P. Lewis, y Toun Planning in Practice (1920) de Raymond Unwin. De las revistas destacaban: Der Städtebau (Berlín), Garden Cities and Town Planning (Londres), La Cité (Bruselas), Landscape Architecture (Cambridge), The American City Magazine (Nueva York),

${ }^{11}$ Cuevas, "Primeras", 1923, p. 69 (cursivas mías) 
L'Habitacion à Bon Marché (Bruselas) y The Town Planning Review (Liverpool). ${ }^{12}$

La lista, sin ser exhaustiva y pese a su magnitud, mostraba un amplio panorama de lo reflexionado y realizado en planeación tanto en Europa como en Estados Unidos, enfatizando cuestiones técnicas, históricas, jurídicas, administrativas, conceptuales, sociológicas, geográficas, arquitectónicas, etc. además de presentar una cierta homogeneidad en las temáticas, como resultado de la fuerte relación entre especialistas a partir de la celebración de congresos y conferencias relacionados con el tema.

Por supuesto, en la lista no aparecía el arquitecto suizo-francés Le Corbusier, quien junto con el historiador de arte suizo Sigfried Giedion, condujeron los influyentes Congresos Internacionales de Arquitectura Moderna (CIAM) (1928) que normaron una época de planeación en Europa y en América Latina, y a quien erróneamente se ha ubicado como el urbanista que a través de la Carta de Atenas de 1933 -publicada en 1942- ${ }^{13}$ influyó en los trabajos de arquitectos e ingenieros mexicanos en esta época, cuando en la realidad no tuvo presencia y sí un rechazo. Al respecto y en lo que ya se abundó en otra

${ }^{12}$ lbid., pp. 69-71.

${ }^{13}$ Eric Mumford, refiriéndose a la publicación de la Carta de Atenas, señala: "El Congreso de la Ciudad Funcional del CIAM finalmente tuvo lugar en el verano de 1933 en el Mediterráneo a bordo del barco SS Patris II, y para el resto de la historia de los CIAM devino en un mítico evento. Los resultados de este congreso, publicados como 'Constataciones' (Observaciones) en un periódico de la Cámara Técnica de Grecia en noviembre de 1933 fueron las bases de lo que Le Corbusier empezó a llamar la Carta de Atenas." Mumford, CIAM, 2000, p. 73. parte, ${ }^{14}$ es oportuno señalar que en el XVI Congreso Internacional de Planificación y la Habitación celebrado en México (1938), Carlos Contreras, quien venía definiendo las líneas de los trabajos de planeación en el país, apuntó:

Es preciso demostrar que es conveniente la descentralización y que en vez de rascacielos y soluciones a la "Le Corbusier", quizás nos convenga más arrasar las manżanas de construcciones miserables e indeseables, reconstruyendo en ellas núcleos de habitaciones de uno, dos y tres pisos con amplios jardines y espacios abiertos y con fácil acceso y cerca del centro de la ciudad para que los empleados y trabajadores que forman un grupo tan numeroso puedan ir a comer a sus casas a pie en vez de hacer ese penoso recorrido en tranvía o camión con duraciones variables de 20 a 60 minutos. ${ }^{15}$

Por las fechas, no hay duda de que la Carta de Atenas era desconocida como tal en México en la década de los años treinta; ${ }^{16}$ y efectivamente influyó en los trabajos de los urbanistas mexicanos pero lo hizo hasta finales de los cuarenta, cuando el movimiento en pos de la planificación declinaba.

Ahora bien, pese a que en los textos enlistados por su antigüedad destaca Planeación de ciudades de acuerdo a principios artísticos (1889) de Camilo Sitte, texto muy influyente entre autores y profesionales de

${ }^{14}$ Sánchez, Planificación, 2002.

15 Contreras, "Informe", 1939.

${ }^{16}$ En su caso quien suscribe el presente escrito, no ha encontrado indicios de que en los años veinte o treinta se citara esta Carta entre los profesionales y estudiosos de las ciudades mexicanas, como tampoco Urbanism (1924) la primera gran obra de Le Corbusier en ese ámbito. 
la época, existen situaciones y personajes que es necesario recordar en tanto sus particularidades y reflexiones constituyeron las primeras inquietudes de lo que se iba a instituir desde fines del siglo XIX, como el arte de planear ciudades y una escuela alemana de la planeación de ciudades. ${ }^{17}$ En efecto, dos personalidades muy ligadas a Camilo Sitte son Reinhard Baumeister (1833-1917) y Josef Stübben, quienes, de acuerdo con Frank Koester en Modern City Planning and Maintenance (1914), cobran importancia debido a que, junto con Sitte, fueron quienes sentaron las bases para dar "un carácter científico al arte de planear ciudades".

En el caso de Reinhard Baumeister, en su obra Stadterweiterungen in technischer, baupolizeilicher und wirtschaftlicher Beziehung (1876), aparecen los gérmenes de lo que como un campo profesional científico se constituirá en la planeación moderna de ciudades, al proponer una estructura razonada que agrupaba aspectos a ser considerados en la naciente disciplina. En el fragmento que de ese trabajo Frank Koester reproduce en su libro, Baumeister delinea lo que posteriormente se convertirá en el concepto de zonificación, al razonar que en la ciudad del futuro tendrían que considerarse tres divisiones íntimamente relacio-

${ }^{17}$ Daniel Burnham en un bosquejo histórico de la planeación de ciudades que hizo en su Plan of C Cbicago (1908) sostenía: "La magnitud del movimiento para la planeación de ciudades en Alemania es tan grande que, literalmente cientos de ciudades sistemáticamente están procesando esquemas de extensión y desarrollo; además dentro de los pasados 25 años, $b a$ crecido una escuela de planeadores de ciudader con hombres como Gurlitt, Stübben, Theodor Fisher y Baumeister, entre otros maestros" (cursivas mías). Burnham y Bennett, Plan, 1993, p. 21. nadas: el centro receptor de negocios, un distrito industrial incluyendo comercio, $y$ un distrito residencial.

Para cada porción de la ciudad proponía calles - principales y auxiliares-, ferrocarriles, canales de drenaje, y algo de fundamental importancia en la posibilidad de planear: el control del suelo a utilizarse en el proceso. Baumeister insistía en que un panorama arquitectónico satisfactorio podía resultar de la simetría en los agrupamientos de edificios, a partir de imaginar puntos apropiados para la observación en calles y plazas, y que ante la monotonía de las calles rectas propuestas para las ciudades modernas, debían recordarse los principios artísticos con que habían sido construidas las ciudades antiguas, donde los anchos de calle no eran monótonos, y se combinaban con plazas y monumentos.

Hacía hincapié en el papel representado por las áreas verdes, apuntando que la previsión de éstas aunado a "una buena relación" con ellas, podía ser un elemento de consolidación de la salud de los habitantes en las ciudades, por lo que sostenía que "la poesía del bosque, el disfrute de caminar y la observación de la naturaleza y el juego inocente de niños con animales", eran buenas evidencias de aquellas aspiraciones. ${ }^{18}$

Joseph Stübben, uno de los planificadores mayormente conocidos en Europa, en su trabajo Principios prácticos y estéticos para el trazo de ciudades (1885), ${ }^{19}$ consideraba tres aspectos como principios prácticos. En el primero, relacionado con el tráfico, abordó el trazo de calles del cual señalaba debían considerarse situaciones

\footnotetext{
${ }^{18}$ Koester, Modern, 1914, pp. 45-49.

${ }^{19}$ Estos principios fueron ampliados posteriormente en su máxima obra, Der Städtebau, 1924.
} 
tanto del presente como del futuro, planteando como necesarias las calles radiales, diagonales y con anillos -aunque no exceptuaba los trazos en damero-; y por otro, plazas para negocios y espacios para otras actividades importantes.

El segundo aspecto era la consideración de las líneas de tráfico que debían comunicar los diversos sectores y que para el caso podían utilizarse las calles anillo, ${ }^{20}$ distinguía esas calles, por su importancia y significación, en de primer, de segundo y de tercer "orden"; ligado a ello y en razón de que las calles radiales y las de anillo formaban entrecruces, señalaba que ahí podían formarse lotes o distritos que cobrarían cierta importancia para los principios estéticos. ${ }^{21}$ En el tercer aspecto refería que, con el objeto de proporcionar salud a sus habitantes, la ciudad debía contar con tuberías para agua potable, sistemas de alcantarillas, luz solar directa, una buena orientación de las calles, viviendas adecuadas, amplias plazas y jardines, límites en alturas de edificios, y árboles que ofrecieran sombra en las calles.

${ }^{20}$ Por supuesto, esta idea de anillos -también señalada por Sitte-, fue retomada en las diversas propuestas de Plano Regulador que Carlos Contreras aventuró para diversas ciudades mexicanas; un ejemplo fue el malogrado y rebasado Anillo de Circunvalación que a fines de los años veinte del siglo en cuestión, propuso para la ciudad de México.

${ }^{21} \mathrm{El}$ ingeniero Modesto $\mathrm{C}$. Rolland en un avanzado trabajo de planeación de ciudades, $E l$ desastre municipal en la república mexicana, editado en 1921, sin dejar de valorar las trazas en damero e intentando mostrar los avances observados en ciudades visitadas, proponía calles radiales como las planteadas para "la ciudad de Washington" o como las de "las ciudades alemanas", apuntando también que al proyectarse las nuevas calles debían aprovecharse sus distintos cruzamientos y generar parques y jardines.
En cuanto a los principios estéticos, Stübben consideraba que la construcción de un plan para la ciudad no sólo debía satisfacer requisitos vitales, sino que también debía considerar "la satisfacción de los habitantes como espectadores de la ciudad", por lo que instaba a cultivar el arte de construir la ciudad, con base en los siguientes principios estéticos: 1. Fomentando elegantes desarrollos de calles conjugando dimensiones, formas derechas y curvas; evitando categorías convexas y espacios desocupados y colocando a los lados de las calles, adornos proporcionados por arbustos, motivos artísticos, u otros. 2. Diseñando edificios en relación con reglas prácticas de uso a partir de los anchos de calle que atendieran la altura de aquéllos; cuidando arreglos de espacios frente a edificios importantes; resaltando lados cóncavos de las calles; considerando monumentos en espacios abiertos a distancias adecuadas, etc. De ahí que apuntara:

Si con el cultivo de la belleza, la asociada influencia del corazón y del alma es ambicionada, nosotros podemos anticipar de la perfección estética y de la construcción de un plan para la ciudad, una rica y venturosa influencia dirigida al estrato de población de la ciudad inclinada a la rudeza; al mismo tiempo, sin embargo, dirigida también para las mentes cultivadas y susceptibles. ${ }^{22}$

La preocupación por el efecto de las actividades y en especial las ligadas con la industria, exigían zonas especiales que afectaran lo menos posible a los habitantes; en ese sentido, estas previsiones apuntadas por Baumeister y Stübben, con el paso de los años y con la asimilación de experien-

${ }^{22} 1$ bid. 


\section{SECUENCIA}

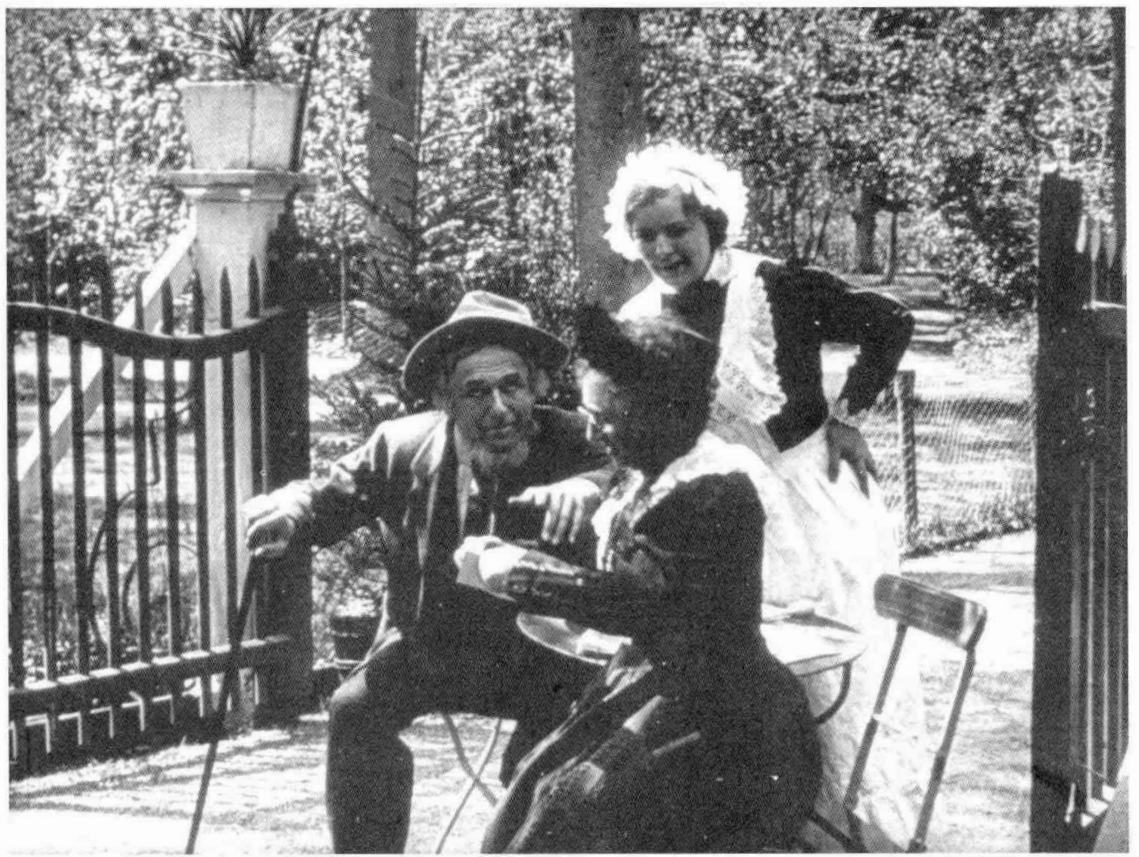


cias, fueron evolucionando hasta llegar a establecer la zonificación, nuevos caracteres para las vías de comunicación, la previsión de áreas verdes y el cuidado de la arquitectura como aspectos de la planeación moderna.

En ese contexto en el que coadyuvan Baumeister y Stübben, se inscribe el libro de Camillo Sitte, quien hizo un análisis resaltando el carácter cívico y artístico de las viejas ciudades europeas para proponer un conjunto de principios con los que desde su punto de vista se podía planear a las ciudades tornándolas modernas. Los aspectos de su ya señalado libro eran: Introducción. I. Las relaciones entre edificios, monumentos y sus plazas. II. Que el centro de las plazas debe mantenerse libre. III. Que las plazas públicas deben ser entidades cercadas. IV. El tamaño y forma de las plazas. V. Las irregularidades de las viejas plazas. vi. Agrupamiento de las plazas. VII a. Calles. vII b. El trazado de las plazas públicas en el norte de Europa. VIII. El magro e inimaginativo carácter de los planos de las ciudades modernas. IX. Sistemas modernos. $x$. Limitaciones artísticas de la moderna planeación de ciudades. XI. Mejoras en los sistemas modernos. XII. Ejemplo de un arreglo urbano de acuerdo con principios artísticos. Conclusión. ${ }^{23}$

El principal aspecto del que derivaba su perspectiva de arreglo de ciudades, era el de aprender lo mejor de las ciudades antiguas, de ahí que en sus más de 200 páginas, reprodujera y analizara ejemplos de ciudades y edificios alemanes, franceses e ingleses, destacando cuestiones estéticas y de funcionamiento, para después proponer una reinterpretación de principios sobre bases modernas, donde destaca su interés en la

$$
{ }^{25} \text { Sitte, "City", 1986, p. } 131 .
$$

conservación de las partes centrales de la ciudad, las que insistía en delimitar con amplias vías y anillos de circulación.

Estos pioneros de la planeación de ciudades en Alemania insistían en un manejo de espacios que consideraba cuestiones funcionales, ambientales y estéticas, pero en un entorno donde Alemania, a diferencia de países como Inglaterra y Francia, con ciudades como Berlín o Frankfurt aún no mostraba fuertes contradicciones; en este país se había prolongado la existencia de las formas feudales de producción, y por ende, la burguesía y su complemento, el proletariado, no se habían volcado sobre las ciudades.

Con esos y otros argumentos, Baumeister, Stübben y Sitte se colocaron como los pioneros de una ciencia que buscaba construir una estructura teórico instrumental que pretendía atender exigencias de una sociedad industrializada que con urgencia necesitaba de espacios para cubrir carencias y aspiraciones; sobre eso, el señalado Frank Koester, al hacer una reflexión de los trabajos de esos pioneros, apunta:

La planeación moderna de ciudades [...] es un nuevo arte basado en principios, teorías y prácticas y sólo recientemente colocadas sobre una base científica. Los maestros modernos son: Reinhard Baumeister, el pionero de la ciencia de la planeación de ciudades modernas; Camillo Sitte, quien formuló sus principios estéticos, y Joseph Stübben, el más grande de los constructores de la ciudad. ${ }^{? 1}$

En esa conjunción de ideas, uno de los textos más conocidos en Europa y Estados Unidos, que ya generaba experiencias de planificación y que causó gran influencia

${ }^{21}$ Koester, Modern, 1914, p. 3. 
en el arquitecto José Luis Cuevas, fue Ciudades jardin del mañana (1898) de Ebenezer Howard. ${ }^{25}$ Este amplio trabajo, citado en todos los textos de historia de la planeación o del urbanismo, pero poco conocido en sus aspectos filosóficos y amplios cálculos económicos con los que se intentaba demostrar la viabilidad de su propuesta, tiene como apartados: Introducción. I. El imán campo-ciudad. II. Los ingresos de Ciudad Jardín y su obtención. La finca rústica. III. Los ingresos de Ciudad Jardín y su obtención. Propiedad ciudadana. IV. Los ingresos de Ciudad Jardín y su obtención. Observaciones generales sobre su distribución. v. Nuevos detalles sobre el presupuesto de Ciudad-Jardín. VI. Administración. VII. La empresa semimunicipal. El concepto de opción local. vIII. Actividades promunicipales. IX. Algunas dificultades observadas. $\mathrm{X}$. Una combinación singular de propuestas. XI. La senda de la reforma. XII. Ciudades sociales. XIII. El futuro de Londres. ${ }^{26}$

Con amplio análisis respecto a la migración del campo a las ciudades, junto al señalado análisis económico, Howard esbozó su proyecto de Ciudad Jardín señalando -con esquemas- que podía considerarse a la ciudad y al campo como dos imanes que atraían gente y que su rivalidad podía ser disipada por una nueva forma de vida que compartiera la naturaleza de las dos. En esa reflexión, como características de la ciudad señalaba: la destrucción de la naturaleza, las oportunidades

${ }^{25}$ En 1925, Cuevas planteó la construcción de la -malograda-primera Ciudad Jardín en Orizaba, además de los "fraccionamientos jardín" Chapuitepec Heights Country Club (1922) e Hipódromo Condesa (1926).

${ }^{26}$ Howard, "Ciudades", 1972. sociales, las aglomeraciones en determinados puntos, espacios de diversión, salarios elevados, altos precios y alquileres, oportunidades de empleo, ejército de desempleados, drenaje costoso, aire contaminado, cielo empañado, buenas calles, bartiadas y palacios; $y$, como características del campo: la falta de relaciones sociales, la belleza de la naturaleza, la holgazanería, largas horas, salarios reducidos, falta de drenaje, abundancia de agua, falta de diversión, brillo del sol, espíritu individual y villas desiertas. Dados esos caracteres, señalaba que lo ofrecido por la ciudad y el campo podía disfrutarse en conjunto, por lo que los dos imanes podían hacerse uno.

Basado en esos y otros argumentos, apuntaba que la Ciudad Jardín podía establecerse en un terreno de 6000 acres en el campo ( 2427.6 hectáreas) ocupando la sexta parte y adoptando una forma circular de 1240 yardas de radio (1 113.85 metros). Proponía en el centro un jardín circular del que partirían seis grandes paseos que atravesarían la ciudad; rodearían al jardín un conjunto de edificios públicos, a saber: ayuntamiento, sala principal de conciertos y conferencias, teatro, biblioteca, museo, sala de arte y hospital; todos en terrenos espaciosos y colocados de manera independiente; $y$, pasando el primer anillo que rodeaba al parque o la Quinta Avenida, una avenida arbolada, localizaba anillos de viviendas con "una variadísima arquitectura".

Dividiendo la ciudad en dos y bordeada por viviendas, escuelas e iglesias, extendía lo que sería la Tercera Avenida o Gran Avenida, también como un cinturón verde, y en el anillo exterior de la ciudad, la Primera Avenida, donde proponía la instalación de fábricas, almacenes, mercados, carbonerías y carpinterías, ligados con una 
vía férrea que también circundaba la ciudad. El resto de ésta estaría dedicado a zonas agrícolas donde se localizarían granjas y fincas, y considerando que en algún momento la ciudad alcanzaría los 32000 habitantes, proponía el establecimiento de nuevas ciudades con similares características, para que en el transcurso de los tiempos se pudiera tener una constelación de ciudades alrededor de una ciudad central. ${ }^{27}$

Como ya se apuntó, en las historias del urbanismo moderno, lo más conocido de Howard son sus diagramas, pero de su filosofía y de los principios para conformar una constelación de ciudades se conoce poco; era una propuesta con amplios tintes del socialismo utópico, por ende, esperanzada en que hombres de negocios apoyaran su propuesta, de ahí que señalara:

He dejado sobradamente claro que la sociedad, a pequeña escala, puede llegar a ser más individualista que ahora (entendiendo por individualismo una sociedad en la que los miembros disponen de las más completas y libres oportunidades para producir y hacer lo que desean y formar libres asociaciones de los tipos más variados) convirtiéndose al mismo tiempo en más socialista. ${ }^{28}$

Pese a los contenidos altamente utópi$c o s$, alrededor de la propuesta de Howard se generaron importantes aportaciones al

${ }^{27}$ Este planteamiento y otros como los de King Champ Gillette en Metrópolis, 1894, Graham R. Taylor en Satellite cities, 1915 y Parrick Geddes en Cities in evolution, 1915, significarían los primeros acercamientos a la perspectiva regional. Seguramente estos planteamientos -por la similitud de los esquemas manejados- fueron retomados por Welter Christaller en su "Teoría de los lugares centrales" plasmada en Die zentralen Orte in Siiddeutschland, 1.933.

${ }^{28}$ Howard, Ciudades, 1972, p. 188. movimiento en pro de las ciudades y las regiones, al surgir la Garden Cities Association (1899) transformada o ramificada en la Garden Cities \& Town Planning Association, y después en la Federation International of Housing and Town Planning, donde se reunirían los más experimentados planificadores de la época y se generarían las experiencias de Letchworth (1903) de Barry Parker y Raymond Unwin; Welwyn (1920) de Louis de Soissons; Radburn, N. J. (1928-1932) de Clarence Stein y Henry Wright, etc. Además de una serie de propuestas con un carácter por demás especulativo, y con denominaciones de garden suburb, garden village, garden settlement, etcétera. ${ }^{29}$

Continuando con algunos de los textos recomendados por Cuevas, en el ámbito estadunidense destaca The improvement of touns and cities (1902) de Charles Mulford Robinson quien, apoyándose en experiencias de París, Viena, Londres, Berlín, y en una perspectiva también de conducir el crecimiento de ciudades sobre bases estéticas, agrupó los aspectos abarcados en su libro, en elementos que permitirían la edificación de una ciudad bella y en trabajos que deberían desplegar las comunidades para concretarlo.

En el primer caso, aborda cuatro cuestiones: el sitio, el plan de calles, el equipamiento, la infraestructura urbana y la arquitectura; respecto al plan para las calles insta a realizarlo siguiendo principios artísticos resaltando las posibilidades que por su simplicidad podían ofrecer calles y

${ }^{29}$ En la ciudad de México se venderían como fraccionamientos jardín las ya señaladas Lomas cle Chapultepec, la Hipódromo Condesa, y colonias mís modernas como la Nueva Santa María y Ciudad Jardín. 
avenidas en damero, en diagonal por la posibilidad de economizar comunicaciones, o de anillos en tanto podían encerrar centros viejos y delimitar otras actividades, además de aprovechar intersecciones para situar fuentes, estatuas, pequeños parques o plazas. Resaltando esa posibilidad en Modern civic art (1903), anotàba: "

Un notable ejemplo de tales grandes avenidas, magnificentemente adornadas con esculturas, es ofrecido por el pequeño Paseo de la Reforma en la cindad de México. Éste es de tres millas de largo y muy ancho. Sobre esta extensión, hay cinco plazas que en París se llaman punto de ronda, en Londres circo, pero los mexicanos le llaman glorieta. El Paseo es diagonal -sobre un plan de parrilla-, y en cada una de éstas está emplazada una escultura dedicada a héroes nacionales. A intervalos regulares de la avenida se levantan pedestales asignados a los estados de. la nación [...], dedicados a héroes; mientras que en las banquetas - y dando hacia la avenidahay un buen número de bancas monumentales de piedra. ${ }^{30}$

Apuntaba que en el plan de calles debían considerarse cuestiones de higiene, tráfico y buen emplazamiento de edificios, exhortando a que los edificios públicos se colocaran alrededor de una plaza central, a diferencia de la costumbre seguida en Estados Unidos. Reforzando ese plan, instaba a que las vialidades posibilitaran mejores condiciones de limpieza, conectaran a toda la ciudad, y a ésta con el exterior, pero no para llevar la ciudad al campo, sino "para atraer el campo a la ciudad". 31

${ }^{30}$ Robinson, Modern, 1903, pp. 225-226 (cursivas mías).

${ }^{31}$ Robinson, Improvement, 1902, p. 139.
En cuanto al equipamiento y a la infraestructura urbana, exhortaba a considerar los sistemas de parques, jardines, paseos y parques-vía porque daban "color a la ciudad"; y por supuesto, colocaba en un lugar preponderante a la arquitectura al considerar que los edificios, fueran nuevos o viejos, definían la imagen en una ciudad y "las formas de vida de su comunidad".

En cuanto al trabajo a desplegar por las comunidades para alcanzar ciudades bellas, instaba a que la ciudadanía recibiera educación en cuestiones de arte para que pudiera valorar los elementos de su ciudad, a la vez que dar su real peso al trabajo que por sus ciudades podía desprenderse del trabajo individual y clel proveniente de asociaciones. Evidentemente, en el escrito existe una preocupación y por lo tanto una especialidad en su perspectiva de la ciudad, en tanto en sus consideraciones prevalecen los elementos físicos y los considerados como estéticos; aunque en una condición de modernidad existe la preocupación respecto a las condiciones de higiene y a la participación social para la construcción de sus ciudades.

Muy ligado al trabajo de Howard se encuentra Town Planning in Practice (1909) de Raymond Unwin, quien tuvo influencias de la Escuela Alemana de la Planeación, particularmente de Camillo Sitte y Joseph Stübben. ${ }^{32}$ El texto tiene como ca-

${ }^{32}$ En el prefacio del texto, Unwin señala: "Estoy particularmente en deuda con el doctor Stübben y el professor Goecke, autor y editor de Der Städtebau; también a Herr Berlepsch-Valendas, y a los funcionarios de muchos pueblos alemanes, que me han dado una gran ayuda a veces diferentes, $y$ han estado muy dispuestos a ayudar a un inglés para que comprenda sus métodos para planificar sus ciudades y sacar provecho de su experiencia." Unwin, Toun, 1994, p. Xx. 
pítulos: I. El arte de cívico como expresión de la vida de cívica. II. De la individualidad de pueblos, con un bosquejo leve del arte antiguo de la planificación de pueblos. III. De la belleza formal e informal. Iv. De la encuesta de ciudad. v. De límites y enfoques. VI. De centros y lugares cercados. VII. Del arreglo de carreteras principales, su trato y planeación. VIII. De la planificación de sitio y los caminos residenciales. IX. De las tramas y espaciado, y plantear edificios y límites. x. De edificios, y cómo la variedad de cada uno debe ser dominado por la armonía del todo. XI. De la cooperación en la planificación del sitio, y cómo el disfrute común beneficia a la persona individual. XII. De desarrollar leyes.

Al igual que Sitte, Unwin hace una semblanza de una serie de soluciones en ciudades y edificios de los que extrae lo que considera cuestiones positivas, que va conjugando con la experiencia de la recién iniciada Letchworth para proponer su reelaboración moderna en la planeación de nuevas ciudades. En el texto se explican las características de Letchworth, donde se conjugaron elementos de la Ciudad Jardín de Howard y de la vieja arquitectura inglesa pero, además, las diferencias de estos autores localizados en los International Housing and Town Planning Congresses con los enrolados en los CIAM en tanto planeación o replaneación de ciudades significaban mejorar los ambientes y elevar las condiciones de bienestar, impulsando el funcionamiento y el embellecimiento de las ciudades.

$Y$ es que no obstante los CIAM defenderán lo funcional sobre lo bello, ambas posturas -aun con sus 18 años de diferencia en su nacimiento- tendrían similitudes. Como nota de esa situación cabe apuntar que en la Declaración de La Sarraz del primer CIAM celebrado en Suiza (1928), los delegados alemanes insistían en cambiar urbanism por city and country planning en los siguientes puntos:

1. Urbanismo es la organización de todas las funciones de la vida colectiva; éste se extiende sobre las aglomeraciones urbanas y el campo [...] La urbanización no puede ser condicionada por las pretensiones de un esteticismo preexistente; su esencia es de un orden funcional. 2. Este orden consiste de tres funciones: vivienda, producción y relajación (mantenimiento de la especie). Los objetos esenciales son subdivisión de la tierra, regulación del tráfico y legisiación de edificios. ${ }^{33}$

Por supuesto, en esas búsquedas por mejorar los procesos de planeación se van dando elementos que incrementan la posibilidad de una planeación más de conjunto, por las propuestas ingenieriles, el diseño, o las reglamentaciones. De ahí lo sobresaliente de los trabajos del ya señalado Frank Koester y de J. S. Nettlefold en Practical Town Planning (1914). En el caso de Koester, éste establece una "visión integral" de la disciplina al considerar cuestiones sociales, estéticas, de diseño y, para el caso, ingenieriles: de ahí su definición de "planificación" donde apunta:

La planeación de ciudades es un tema de muchas ramificaciones y cubre un campo mucho más amplio del que generalmente se le supone, incluye no sólo el embellecimiento estético de la ciudad sino también la construcción y coordinación de todos los elementos que van a hacer de la ciudad moderna un mecanismo práctico y operativo. ${ }^{34}$

\footnotetext{
${ }_{33}^{3.3}$ Mumford, CIAM, 1994, p. 25.

${ }^{34}$ Koester, Modern, 1914, p. vI.
} 
$Y$ en el caso de Nettlefold, un elemento importante es la idea de "reglamentar el uso del suelo", en tanto lo consideraba un elemento central para posibilitar la elaboración de planes, por lo que en su texto resalta una serie de aspectos que deben considerarse en "políticas de planeación de ciudades", que resume así:

1. Ofertar tierra barata para edificios y otros propósitos [...] 2. Proteger a esas tierras de excesivos incrementos en valores para evitar presiones sobre ellas. 3. Proteger a los contribuyentes en contra de precios exorbitantes por tierra requerida [...] 4. Rentar tierra a trabajadores (no venderla) para vivienda, repartos y pequeñas parcelas [...] 5 . Reformar el sistema de impuestos disminuyéndoselos a la industria y colocar un cargo razonable sobre aquéllos quienes permiten que su tierra permanezca ociosa. ${ }^{35}$

Señalados esos aspectos, apunta que si esas normas eran observadas, la planeación podría ampliarse y mejorarse al impulsar el pago de impuestos bajos para la población, mejores negocios, mayor salud y excelentes ciudades.

De una perspectiva más sociológica es Cities in Evolution (1915) de Patrick Geddes, quien proporcionó nuevos bríos a la planeación de ciudades y ya de regiones, al plantearse "nuevos horizontes metodológicos" y por lo tanto, nuevas tareas para el estudio y tratamiento de esos ámbitos. En su texto propone la manera en que debían estudiarse los territorios dosificando los apoyos brindados por la historia y privilegiando estudios más contemporáneos, sin perder la perspectiva del futuro; $y$ por otro -como una de sus mayores aportacio-

${ }^{35}$ Nettlefold, Practical, 1914, p. 238. nes-, se plantea la posibilidad de construir nuevas perspectivas para esos estudios, generando el concepto de conurbación.

Como otros estudiosos, Geddes resalta el interés cobrado por los fenómenos en las ciudades y sus alrededores, e insiste en que los métodos tradicionales ya no alcanzaban a visualizar los nuevos problemas y que por lo tanto había que renovarlos; en ese sentido ponderaba el hecho de que una nueva ciencia o arte social se estuviera formando pero que además involucrara a estudiosos de lo social, parlamentos, prensa, "lo más atrasado de los consejos del pueblo", y al "más indiferente de sus contribuyentes". ${ }^{36}$ En esa vía, más que cuestionarse desde dónde debían empezarse a estudiar las ciudades o cómo, insistía en preguntar "¿qué sigue?".

Por otra parte, fustigaba el hecho de que los estudiosos de ciudades no aquilataran la belleza de calles y por lo tanto, mantuvieran una cierta "ceguera" ante sus deterioros y la mejora de sus elementos; además que no valoraran la posibilidad de que las ciudades con sus viejas culturas pudieran ser objetos de aprendizaje "y no simplemente fenómenos de la decadencia".

Refiriéndose a la forma de evolucionar del Gran Londres, Geddes resaltaba dos características, que se extendiera como una "amiba" o como una "provincia cubierta de casas" absorbiendo gran parte del sudeste de Inglaterra, y que pese a todo, se mantuviera el Londres histórico y tradicional. En ese sentido, cuestionaba los límites de la ciudad por ser inoperantes apuntando que debían modificarse en términos de los nuevos usos y actividades, pero en una condición donde en "lugar de las líneas

${ }^{36}$ Geddes, Cities, 1968, p. 2. 
viejas de división" se trazaran "nuevas líneas de unión".

Aparte de los estudios de historia, sugería análisis de viejas, nuevas y futuras áreas de residencia para ricos, clase media y pobre, y nuevas formas de gobierno con atribuciones más amplias con el fin de abarcar jurisdicciones superadas por el crecimiento de lo habitado y permitir relaciones más funcionales entre Londres y su provincia. Como una de las exigencias que iba solidificando la naciente ciencia, reflexionaba que hacer esos arreglos para lo que consideraba vida, salud y eficiencia, eran necesarios acuerdos entre los entes involucrados.

En su inquietud por explicar los nuevos fenómenos, junto al caso de Londres, aborda los de Manchester, con su gran comercio; Liverpool, puerto de entrada y salida de productos, y Oldham con sus zonas industriales, ciudades que con grandes densidades de población y que al extenderse a través de las vías de comunicación, estaban formando "provincias cubiertas de casas". Por lo que al buscar "aclarar ideas antes de concebir políticas", aventura su concepto de conurbación para estas nuevas situaciones, el cual definió así:

Para enfocar estos desarrollos y por tanto sus transformaciones, necesitamos de la tradición geográfica de la ciudad y país en que nos formamos y una pequeña ampliación de nuestro vocabulario [...] Algún nombre, entonces, es deseado para estas ciudadesregión, estos pueblos agregados. Constelaciones no podemos llamarlos; conglomerados, ¡no puede ser! Pero pueden denominarse "conurbaciones". Eso quizás puede servir como una expresión de esta nueva forma de agruparse de la población, la cual en sí misma, está desarrollando nuevas formas de agrupación social, de gobierno y de administración. $^{37}$

Por supuesto, hacía la mención de que esos nuevos reordenamientos podían representar disputas y roces, dificultades legales y erogaciones económicas; por lo que señalaba que era tiempo para la cooperación de geógrafos regionales, higienistas, "el sociólogo concreto", y todos los que estudiaban al país, ciudades, pueblos y villas.

Siguiendo estos textos recopilados por Cuevas, uno de los más influyentes entre los mexicanos y particularmente en Carlos Contreras, fue New Ideals in the Planning of Cities, Touns and Villages (1919) de John Nolen. El texto resume muchos de los aspectos que de la planeación de ciudacles venían consolidándose en Europa y Estados Unidos. Señalaba que el despertar alcanzado por la planeación no era un movimiento vago de objetivos imprécisos e indefinidos, que se trataba de un movimiento para suministrar conveniencias a calles y edificios, cubrir requisitos de la salud, reconocer la función verdadera y el lugar del arte, tratar las obligaciones para futuras generaciones, satisfacer necesidades imperativas de niños, el amor por la naturaleza y el deseo por la vida al aire libre. En esa vía enfatizaba lo que debía abarcar la "planeación de ciudades", al señalar:

La planificación diestra debe enfatizar la individualidad para una ciudad justo como la verdadera educación alcanza a un niño. Debe desarrollar y perfeccionar las características naturales. Debe tomar en cuenta la topografía de una ciudad, mantener sus características naturales, hacer eco de los propósitos de la empresa, expresar su riqueza, dar forma

${ }^{37} \mathrm{Ibid}$., p. 35. 
a sus tradiciones, ideales y aspiraciones. Un plan para la ciudad digno de ese nombre, debería cuidar la tendencia al manejo arbitrario que hace de la ciudad un lugar pernicioso. $^{38}$

En el mismo camino, apuntaba que para atender a la planeación o "replaneación" de ciudades, debían realizarse "estudios" cuidadosos de las "condiciones físicas, económicas y sociales" a partir de "inventarios y encuestas" y, visualizando dos grandes propósitos: la preservación y el desarrollo de lo que consideraba la "individualidad de la ciudad" atendiendo su historia, condiciones físicas, población, $\mathrm{y}$ tendencias de su industria o comercio y elevar el bienestar social. En esa vía subrayaba: " $\mathrm{El}$ individualismo fuerte, egoísta y casi no controlado todavía prevalece en nuestras ciudades, y muchos de los males pueden ser corregidos por una mejor planeación." 39

Insistía en que para ofrecer un plan para la ciudad no sólo era necesaria una maquinaria administrativa que pudiera revisarlo, actualizarlo y ejecutarlo, sino que debía considerar "su costo". Con esa determinante, exhortaba a tener en mente que las ciudades se desenvolvían entre prioridades, que tal vez se podía preferir el pago de costos directos e indirectos de los impactos de epidemias, a invertir en agua pura, alcantarillas, vivienda y otras cuestiones, pero que razonar así era estrecho y mezquino. Por lo que apuntaba que los principios generales para gobernar los preparativos de un plan, debían ser: asegurar resultados deseados con un mínimo de recursos económicos y considerar los inte-

\footnotetext{
${ }^{38}$ Nolen, New, 1919, pp. 10-11.

${ }^{39}$ Ibid., p. 17.
}

reses de quienes contribuían con sus impuestos para la ciudad; todo ello, previendo requerimientos a futuro.

Hechas esas reflexiones, consideraba como los principales tópicos de la planeación: la encuesta local como base para el urbanismo; los elementos esenciales de los planes de ciudad, incluyendo calles y caminos, tranvías, ferrocarriles de vapor, canales navegables de comercio y costas; la subdivisión de la región y el desarrollo de bienes raíces; la división de una ciudad en zonas o distritos, parques, patios de recreo, y otras áreas verdes públicas; las organizaciones públicas y semipúblicas y los aspectos de planeación de viviendas; los tipos de planes de ciudad; nuevas ciudades y estándares; el financiamiento de los proyectos; legislación y organización; la formación de profesionales en el ámbito; y lo que denominaba la promesa del futuro.

Apuntado esto, resaltaba tres fases en el proceso que llevaría la confección de un plan, una de "propaganda y discusión"; otra de los "preparativos de un informe y un plan general" donde se presentaban propuestas; y finalmente, la de "elaboración de esquemas o planos".

En este evolucionar - presentado aquí a grandes rasgos- se adquiría mayor maduración en la estructura y los aspectos abarcados por la planeación; se coincidía en que la planeación requería científicos sociales y técnicos con trabajo de conjunto; se enfatizaba en la atención a problemas vitales como la insalubridad, la falta de vivienda y la necesidad de espacios para la industria y de actividades que de ésta se generaban; se exhortaba a separar funciones y relacionarlas adecuadamente con calles y avenidas; se instaba a cuidar la imagen de las ciudades, en particular de sus centros históricos; se exhortaba a conside- 
rar variables como la administración, lo jurídico, la cuestión del suelo, el poder político, etc. Esos avances indudablemente solidificaban a la nueva ciencia, de ahí definiciones más elaboradas como la de Thomas Adams, quien inscribía:

Planeación de ciudades y pueblos es una ciencia, un arte y un movimiento de políticas referentes a la formación y guía del crecimiento físico de áreas, en armonía con sus necesidades económicas y sociales. Consideramos a esto como una ciencia para obtener conocimientos de la estructura urbana, los servicios y la relación de sus partes integrantes con procesos; como un arte para determinar el trazado de la tierra, los arreglos de usos de tierra, las vías de comunicaciones y la eficiencia de su desarrollo; y como un movimiento de políticas para dar efecto a nuestros principios. ${ }^{40}$

Éstos eran algunos de los aspectos con los que se relacionaron quienes realizaron las primeras propuestas y acciones en las ciudades mexicanas, otros se derivaron de su asistencia y relación con los congresos y conferencias que sobre planeación de ciudades y regiones tenían lugar en varias partes del mundo.

\section{ENCUENTROS QUE INFLUYERON EN LA PLANIFICACIÓN REALIZADA EN MÉXICO}

Una condición que solidificó el movimiento en pos de la planeación de ciudades, fue la celebración de conferencias y congresos, porque ahí se afianzaron intercambios de experiencias en ámbitos nacionales e internacionales, se homogeneizaron con-

${ }^{40}$ Adams, Outline, 1935, p. 21. ceptos y se solidificó una estructura para la planeación. Para el caso, fueron importantes las reuniones impulsadas por la Garden Cities Association (1899), como la Garden City Conference en Bournville (1901); pero las más notables fueron: The First National Conference on City Planning (1909) en Washington y The Great International Town Planning Conference (1910) organizada por The Royal Institute of British Architects (RIBA) en Londres, de la que se derivaron los ya señalados congresos de International Housing and Town Planning que se realizaron hasta entrados los años cincuenta.

La Great International Town Planning Conference fue la reunión más importante en el ámbito de la planeación de estos años, al generar un movimiento que agrupó a países y a personajes como: Joseph Stüben, Patrick Geddes, Louis Bonnier, Thomas Adams, Eugène Hénard, Ebenezer Howard, Raymond Unwin y Daniel Burnham. Como uno de sus resultados, la RIBA redactó un documento al que denominó: "Sugestiones a promotores de esquemas sobre planeación de ciudades", con los siguientes aspectos: I. Estudios cívicos. II. Estudios técnicos. III. Nuevas instalaciones para el tráfico. IV. Centros principales y secundarios. v. Centros de tráfico. VI. Sistema de carreteras principales. vII. Carreteras secundarias. VIII. Carácter y tratamiento de carreteras. IX. Áreas reservadas para propósitos especiales. $\mathrm{x}$. Espacios abiertos, y Xr. Edificios.

Esos aspectos prefiguraban una estructura metodológica que fue retomada en textos y esquemas de planeación de muchos países incluido México. En ésta se siente una preocupación por lo físico de las ciudades, la interpretación de lo social y la consideración de escenarios futuros, 
tal como lo muestra la justificación que se hace en la parte denominada "Estudios cívicos", donde se apunta:

Así como el esquema de planeación debe dirigir y limitar el desarrollo del área a la que se aplica, el éxito sólo puede esperarse si es basado en un estudio final y la comprensión de todas las condiciones existentes. Tal estudio debe recoger el estado físico del sitio, deben cubrir las condiciones económicas y sociales de la población, y los aspectos histórico y arqueológico de interés asociados con la localidad, y sus edificios. ${ }^{41}$

Otras situaciones que pueden subrayarse del documento son: el énfasis en "los estudios cívicos preliminares" (lo social y económico); lo que viene prefigurándose como zonificación al insistir en la delimitación de centros apropiados para gobierno, administración, comercio, educación, industria, vivienda, plazas, etc.; las previsiones para usos especiales de la ciudad; el nivel alcanzado por los medios de locomoción especialmente trenes y automóviles; los sistemas mecánicos que daban nuevos bríos a la industria de la construcción; y finalmente, la manera en que se enfatiza el papel de la arquitectura, ${ }^{42} \mathrm{al}$ señalar: "El problema de la planeación de ciudades en su forma final, sea la que sea, es un problema arquitectónico." ${ }^{43}$

\section{${ }^{41}$ Reps, City, 2002.}

${ }^{42}$ Aquí convendría denotar que el común de la gente y a veces la no tan común, relaciona la arquitectura sólo con fachadas y planos cuando es mucho más que eso. Es condensación de relaciones sociales, expresión cultural e histórica, materialización o frustración de aspiraciones, elemento de identidad, envoltura de actividades. $O$ si se quiere, construcción social o imaginarios sociales de cada época.

${ }^{43}$ Reps, City, 2002.
Esta forma de disgregar a las ciudades para su estudio y atención, dibuja el grado de comprensión que venía adquiriendo la disciplina. Si las ciudades no habían requerido más que las apreciaciones y las acciones que hasta hacía seis décadas atrás se habían dado, era porque el desenvolvimiento de las ciudades no lo había exigido; si se presentaron preocupaciones por los espacios habitados al final del siglo XIX era porque los problemas crecían; si se pasaba de apreciaciones y propuestas particulares a visiones más consensuadas y de conjunto, era por la necesidad de controlar conjuntos más extendidos y más complejos, y si se exigía una mayor intervención del Estado, era porque la planeación requería órganos con poder de decisión y con acceso a vastos recursos.

Esa conferencia de 1910 dio lugar a subsecuentes reuniones convertidas en los IHTPC; de las que para el pensamiento planificador en México fueron importantes las de 1925,1935 y $1938 .{ }^{44}$ La de 1925 fue una reunión doble pues en Nueva

${ }^{44}$ Algunos de esos congresos tuvieron como grandes temas los siguientes, Amsterdam (1924): 1. La planeación regional y la vida de las grandes ciudades. 2. Proyectos regionales. 3. Sistemas de parques y recreación, y 4. Los transportes dentro del plan regional. Viena (1926): 1. Formas de la tenencia de la tierra y la planeación regional. 2. El proyecto racional de las habitaciones familiares y de los apartamentos. 3. La habitación después de la guerra. París (1928): 1. El precio de la construcción de viviendas. 2. Vivienda rural. 3. Prácticas legales dentro del establecimiento de un plan de ciudades y de un plan regional. 4. Masa y la densidad de la vivienda y el provecho de espacios libres. Roma (1929): 1. Desarrollo histórico del Plan de Roma. 2. Recursos financieros para la vivienda de la clase obrera y de las clases medias. 3. Planeación de viviendas colectivas. 4. La renovación de ciudades antiguas e históricas para responder a condiciones 


\section{SECUENCIG}

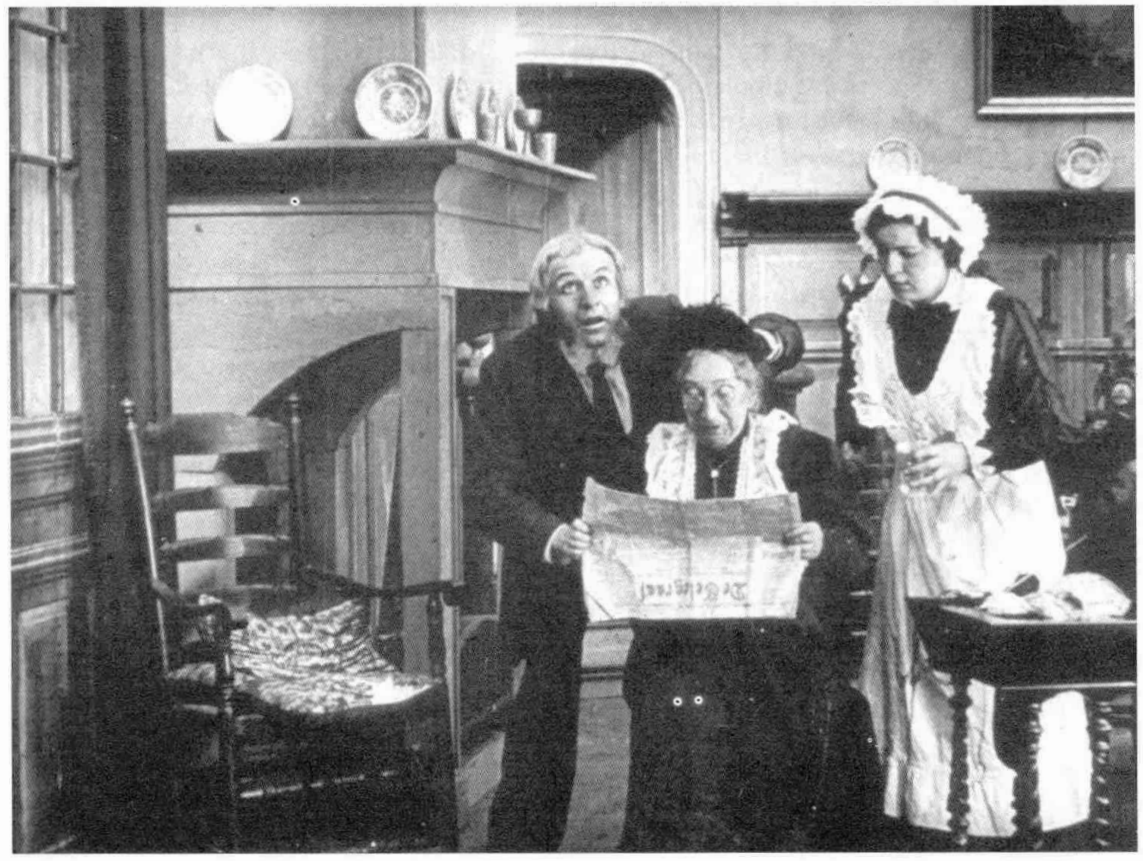


York, el IHTPC se agregó a la Conferencia Nacional de Planeación Regional y de Ciudades que continuaba las iniciadas en Estados Unidos en 1909, donde como grandes temas se presentaron: 1 . El problema del tráfico. 2. Descentralización en regiones. 3. El Plan Regional para Nueva York. 4. Planes típicos de ciudad. 5. Proyectando con fotografía aérea. 6. Planeación en áreas no construidas. 6. Zonificación en práctica. 7. Adquisición de tierras beneficiadas por mejoras públicas. 8. La evaluación económica de la planeación regional y de ciudades. ${ }^{45}$

A esta reunión asistió una delegación mexicana encabezada por el ingeniero Ignacio López Bancalari representando al gobierno de México, el arquitecto Federico E. Mariscal y el licenciado Vicente Lombardo Toledano representando al Ayuntamiento de México, y los arquitectos Bernardo Calderón y Caso, José Luis Cuevas, Antonio Muñóz G., Carlos Obregón Santacilia y Carlos Contreras, representando a la Sociedad de Arquitectos Mexicanos. ${ }^{46}$ La inauguración la hizo Sullivan Jones representando al gobernador de Nueva York, Everett Waid presidente del Instituto Americano de Arquitectos y Ebenezer Howard; y como tema introductorio se plantearon "los progresos en la planeación", en el que participaron, entre otros, George B. Ford, Raymond Unwin, Josep Brix y Carlos Contreras.

modernas. 5. Métodos de planeación para la expansión de ciudades, especialmente de villas antiguas e históricas. 6. El desarrollo de Milán. Y Berlín (1931): 1. La abolición de Tugurios. 2. El problema del tráfico para provecho de la planeación urbana y regional. 3 . Lecciones de los pasados congresos.

${ }^{45}$ Coolidge, Problems, 1.925.

${ }^{46}$ Contreras, Informe, 1939.
En su intervención Contreras hizo una semblanza de los esfuerzos realizados en México desde la planeación de Tenochtitlan, a la que comparó con una ciudadjardín, lo que se realizaba en la capital mexicana al crearse la Comisión de Planificación en el Ayuntamiento (1925), y lo que en ese momento eran avances en el conocimiento del territorio y de la ciudad de México. Para ello el gobierno mexicano, por medio de la mencionada delegación, distribuyó entre delegados de la conferencia una serie de documentos resumidos como sigue:

200 ejemplares del Álbum de Obras Materiales, ejecutadas por la Federación Mexicana de 1919 a 1924; 200 copias fotográficas del Plano de 1793 de la ciudad de México; 60 fotografías del edificio del Departamento de Comunicaciones y Obras Públicas y del teatro Nacional; 25 copias azules del Departamento de Obras Hidráulicas y Edificios; dos colecciones de nueve volúmenes cada una con 1000 fotografías [...]; 50 ejemplares de la obra La bigiene en la ciudad de México por el ingeniero Alberto J. Pani, secretario de Hacienda y Crédito Público. ${ }^{47}$

Si bien en lo obsequiado aparece el interés por mostrar parte de la riqueza urbana y arquitectónica del país, y algunos de los trabajos que se estaban desarrollando, no existía nada consolidado respecto al estudio y a la planeación de ciudades; sin embargo, estaba el interés que finalmente llevó a los trabajos de conceptualización, propagandización y atención de ciudades que van a destacar desde fines de esos años veinte.

${ }^{17}$ Contreras, "Informe", 1925, pp. 36-37. 
La versión XIV de esos congresos tuvo lugar en Londres en 1935, donde se abarcaron como grandes temas: 1 . Nueva vivienda para la gente. 2. Planeación positiva, y 3 . Desarrollo rural planeado y la preservación del campo; asistieron entre otros: John Nolen, G. L. Pepler, E. P. Everest, Patrick Abercrombie, Raymond Unwin y Carlos Contreras, representando al gobierno de México.

De acuerdo con la relatoría que hizo Patrick Abercrombie, los aspectos discutidos y sobresalientes fueron: las perspectivas de la planeación con orientaciones que insistían en tratamientos regionales y por país; los instrumentos de la planeación, entre los que se destacan las normas jurídicas que pretendían normar la propiedad del suelo; los marcos de acción de los organismos implicados en la planeación, clamando por la centralización del poder pero impulsando la acción de órganos locales autónomos y con participación comunitaria, y los problemas del financiamiento.

En esas preocupaciones, Carlos Contreras resaltó la experiencia vivida en cuestión de vivienda en la ciudad de México, al impulsar el Departamento del Distrito Federal la construcción de los conjuntos obreros de Balbuena, San Jacinto y la Vaquita; y describir los apoyos legales y la formación de órganos planificadores con los que se intentaba conducir el desenvolvimiento de la ciudad de México. Respecto a esto último -resaltado por Abercrombie en la relatoría-Contreras, apuntaba:

La ciudad de México tiene su Ley de Planificación desde enero de 1933, su importancia estriba en la creación de los Comités Ejecutivos con los que se llevan a cabo mejoras locales, aprobadas por la Comisión de Planeación de la ciudad. Estos comités locales son nombrados por la Comisión y son compuestos por tres o cuatro de los más prominentes propietarios afectados por las mejoras. Se hace un esfuerzo para obtener la participación de éstos, quienes aportarán amplias cantidades posibles o presentarán la más seria objeción a la idea, para que con su convencimiento, demos un gran paso en la ejecución del proyecto. El Comité no recibe pago pero es asistido por un consultor técnico pagado. ${ }^{48}$

En la clausura del evento, aparte de recapitular respecto a lo expuesto en las distintas sesiones, se trató el tema de la sede de la próxima reunión, manifestándose $G$. L. Pepler en el sentido de que Sudáfrica fuera la sede en 1937, por lo que el arcjuitecto Contreras apuntó:

Estoy seguro que México invitará a la Fecleración a celebrar en congreso en México en 1937 [...]. Estoy seguro que el gobierno mexicano y el gobierno de la ciudad de México harían todo de su parte para dar las facilidades para el congreso. ${ }^{49}$

Seguramente hubo consultas y acuerdos de apoyo, en tanto el influyente doctor John Nolen, presidente del congreso, apuntaló la propuesta de Contreras asentando: "Si es posible considerar la propuesta mexicana, creo que podría combinarse con ello un congreso en Estados Unidos", ${ }^{50}$ aunque finalmente México celebraría la cita XVI de estos congresos en 1938.

Y en efecto, entre los días 13 y 27 de agosto de 1938 en el Palacio de Bellas Ar-

\footnotetext{
${ }^{48}$ International, XIV, 1935.

${ }^{49} \mathrm{Ibid}$.

${ }^{\text {so }}$ lbid.
} 
tes de México, tuvo lugar el XVI International Housing and Town Planning Congress, contando con el apoyo del general Lázaro Cárdenas, quien desde 1935 había autorizado las gestiones para su celebración en México. Los temas fueron: 1. La planificación subterránea. 2. Los problemas de la habitación en los países tropicales y subtropicales, y 3. La planificación, la recreación y el uso del tiempo iibre. Y como temas adicionales: 1. La enseñanza de la planificación, y 2. La planificación nacional.

El directorio del Congreso lo conformaron Carlos Contreras como presidente, el ingeniero José A. Cuevas como secretario y el arquitecto Carlos Tarditi como tesorero; y en el Comité Honorario compuesto por miembros de diferentes países, figuraban el ingeniero Javier Sánchez Mejorada y Aarón Sáenz dos funcionarios impulsores de este movimiento en pos de la planificación en México. Al congreso asistieron 535 delegados procedentes de Guatemala, Estados Unidos, Cuba, Argentina, Colombia, Inglaterra, Nueva Zelanda, Canadá, Francia, Holanda, Suiza y México, y tocó a José Siurob, jefe del Departamento del Distrito Federal, dar en nombre del gobierno mexicano la bienvenida, quien señaló:

México abre en esta ocasión sus puertas hospitalarias para recibir engalanados a los delegados que el mundo le envía, mensajeros de cultura y de paz, portadores del intenso palpitar de otras ciudades y de otros pueblos, que erigen sus realizaciones magníficas en arquitecturas de maravilla y ostentan con orgullo las nuevas formas de plasmar en conjunto las bellezas, las necesidades, las ansias y los anhelos de la vida moderna [...] Aquí donde se siente el hálito de los siglos al con- templar las viejas ciudades toltecas, las pirámides del Sol y de la Luna, el maravilloso trazo de las ciudades de Uxmal y Chichén Itzá, podréis contemplar la cultura medieval de las viejas catedrales, de los místicos conventos, de los pesados acueductos que como el de Querétaro, levantan airosos sus arcadas esbeltas bajo las cuales pasa la moderna locomotora, hermanando así en estrecho abrazo el hoy con el ayer. ${ }^{51}$

Ese discurso es significativo por el papel que el doctor José Siurob le otorgaba a la organización de ciudades, a las posibilidades del progreso, al legado urbano y arquitectónico del pasado y a la posibilidad de ser modernos; a la vez que mostraba el ambiente político y social del país. Estas situaciones son patentes en la continuidad del discurso, al señalar:

Es nuestra divisa y será nuestra gloria cuando dando un paso en el tiempo podamos como vosotros lo habéis hecho en vuestros países, levantar las nuevas ciudades como nidos más confortables y bellos donde pueda desarrollarse la vida integral del cuerpo y del espíritu a fin de que las nuevas generaciones encuentren el modo de cristalizar sus esperanzas de libertad y de justicia, aboliendo la guerra, acabando con las explotaciones del hombre por el hombre, poniendo en planos posibles de igualdad y fraternidad las más nobles, las más legítimas aspiraciones humanas. $^{52}$

Por ser país sede destacaron los delegados mexicanos, entre ellos: Álvaro Aburto, Roberto Álvarez Espinosa, Enrique Aragón Echegaray, Raúl Cacho, Mauricio M.

s1 Contreras, Informe, 1939.

${ }^{52}$ Ibid. 
Campos, Domingo García Ramos, Luis González Aparicio, Enrique Guerrero, Carlos Leduc, Federico E. Mariscal, Enrique de la Mora, Enrique del Moral, Antonio Muñoz García, Carlos Obregón Santacilia, Manuel Ortiz Monasterio, Alfonso Pallares, Mario Pani, Luis Prieto y Souza, Juan Segura, Juan Sordo Madaleno, Vicente Urquiaga y Enrique Yáñez; los ingenieros: Vito Alessio Robles, Luis Barragán, Enrique A. Cervantes, Manuel González, Eduardo Molina, Miguel Ángel de Quevedo y Enrique E. Schulz; además de Justino Fernández, Edmundo O'Gorman y Manuel Toussaint. ${ }^{53}$

Entre las intervenciones, de la parte mexicana destacaron la del ingeniero José Antonio Cuevas, quien resaltó un aspecto que empezaba a ser preocupante para la urbanización: la proliferación de edificaciones y apertura de pozos artesianos que provocaban hundimientos en la ciudad de México; la del licenciado Adolfo Zamora, quien proponía en materia de vivienda "impulsar la construcción multifamiliar frente a la unifamiliar"; la del ingeniero Miguel Ángel de Quevedo, quien resaltó los esfuerzos desplegados en la "Comisión de Embellecimiento y Mejoras" del Ayuntamiento de la ciudad de México desde 1901, donde con la idea de higienización propuso arborizar avenidas, parques y jar-

${ }^{53}$ Esta notable participación de los ingenieros y arquitectos de México muestra el nivel de convocatoria que logró el congreso, y el interés por la nueva disciplina, y es que las condiciones del país exigían escudriñar teorías y prácticas de quienes estaban transformando sus ciudades, de ahí tal vez el interés que redundó en personas que posterjormente destacarían como urbanistas, tal como ocurrió con Domingo García Ramos, Raúl Cacho, Vito Alessio Robles y Enrique A. Cervantes. dines, y la de Luis Sánchez Pontón, ${ }^{54}$ quien resaltó lo imperioso de los trabajos interdisciplinarios, al asentar:

No se necesita gran esfuerzo para encontrar los puntos de contacto de estas disciplinas científicas con las que ustedes -ingenieros y arquitectos- cultivan y que han sido expuestas tan brillantemente en esta Asamblea. El Derecho y la Sociología, a la vez que recogen con atención creciente las manifestaciones de la ingeniería aplicada al mejoramiento de las ciudades, del territorio en general, y con él, a crear condiciones de vida más humanas para las grandes masas de población, deben ser vistos como auxiliares indispensables para llevar a la práctica los principios de la planificación y del urbanismo. ${ }^{55}$

Una participación destacada por parte de los mexicanos fue la de Nicolás Mariscal, quien en una postura muy objetiva subrayó el hecho de que a los términos planificación y plantificación, se les tuviera que agregar el término ciudad, para connotar trabajos en las ciudades -olvidando lo planteado por Contreras doce años antesy propuso usar la palabra urbanización, término al que dio el significado de "hacer ciudades". Otra de las participaciones de interés fue la de José Luis Cuevas, quien apuntó la necesidad de crear una academia o un instituto para enseñar planificación y urbanismo, situación que bajo su guía redundó en el malogrado Instituto Superior de Planificación y Urbanismo (ISPU) creado en la Escuela Superior de Ingeniería y

${ }^{54}$ El licenciado Sánchez Pontón era miembro y fundador de la Asociación Nacional de Planificación en México y en su tiempo había sido un activo regidor en el Ayuntamiento de la ciudad de México.

ss Contreras, Informe, 1939. 
Arquitectura del Instituto Politécnico Nacional que funcionó entre 1939 y 1941.

Todas esas ideas y situaciones fueron confluyendo en nuevas perspectivas y experiencias en los estudios urbanos y regionales, y por supuesto en el caso de México generaron trabajos muy significativos. De las experiencias -contadas en estos años por cientos- las más significativas fueron las de Letchworth (1903) y Welwyn (1920) diseñadas por los arquitectos Barry Parker y Raymond Unwin la primera y por Louis de Soissons la segunda; el Plan de Chicago (1909) de Daniel Burnham y Edward H. Bennett, el Plan de Rotterdam (1914) de Hendrick Petrus, el Plan Regional de Nueva York y sus Alrededores (1929) dirigido por Thomas Adams, y el Plan para el Gran Londres (1944) de Patrick Abercrombie.

En el caso de México, se sucedieron proyectos como el de La Planificación de la República Mexicana de 1925, la conformación de la Asociación Nacional para la Planificación de la República Mexicana de 1926, el Estudio Preliminar No. 1 del Plano Regulador de México, ${ }^{56}$ el Plano Regional del Distrito Federal y la Ley de Planificación de Monterrey de 1927, la Ley sobre Planeación General de la República de 1930, la Ley de Planificación y Zonificación del Distrito Federal y Territorios de Baja California de 1933 y similares de otros estados, el Plano Regulador para el Distrito Federal de 1933 y los planteados para otros estados, junto a las obras que de aquellas situaciones se derivaron.

\footnotetext{
56 Sólo para mostrar los alcances de algunas de estas propuestas, cabe apuntar que este plano -con los consecuentes replanteamientos- fue finalmente aplicado a través del proyecto de Ejes Viales, entre los años de 1978 y 1981 .
}

\section{UNA REFLEXIÓN FINAL}

No obstante los avances, las teorías reflexionadas y las acciones instrumentadas, a partir de los años cuarenta la perspectiva y las posibilidades de la planificación decayeron en México. En el hecho se conjugó una serie de determinantes entre las que destacan: la manera en que partes significativas de la sociedad mexicana fueron insertándose en la nueva modernidad, concentrando actividades en las principales ciudades de México, particularmente en su capital; la dinámica de esa concentración donde grupos empresariales en la búsqueda de ganancias fáciles pasaron por alto delimitaciones, normas y arreglos propuestos para las ciudades, además de especular con éstas; el declive de los planificadores ante un desarrollo desigual estimulado por los capitales; y la generalización a partir de los años sesenta de estudios urbanorregionales procedentes de las ciencias sociales y aun desde la arquitectura, donde con fundados argumentos se criticaron las disparidades territoriales, caracterizando a la planificación como un instrumento al servicio de grupos dominantes.

Lamentablemente en esto último no se rescató lo valioso de aquel movimiento en pos de la planificación, en tanto buena parte de quienes pudieron hacer historia de las ciudades cayeron en las descripciones de la apariencia: calles, aveniclas, edificaciones, espacios abiertos; y no insistieron en la esencia: las aspiraciones que se pretendieron atender, los contextos en que la planificación se desarrolló, las fuentes teóricas y prácticas a las que se acudió -en alemán, inglés y francés y con pocas traducciones-, los estudios sociales y técnicos realizados, etc. Más aún, gran parte de la historia urbana se moldeó por lo que se pudo traducir 
sobre todo de la Carta de Atenas y la Escuela de Chicago, y muchos años después de que el movimiento encabezado por la Asociación Nacional para la Planificación de la República Mexicana decayera.

Aun así, muchas de las reflexiones de personalidades como Contreras y Cuevas se tradujeron en planos - planes para nuestra concepción actual-que sirvieron para intervenir entre los años veinte y cuarenta, en ciudades como Monterrey, Acapulco, Veracruz, Aguascalientes, San Luis Potosí, Guadalajara, Mérida y la ciudad de México. Esas intervenciones -que aún se encuentran sin documentar-, se convirtieron en los cimientos de una modernidad que, pese a sus condiciones desiguales, discurrió a lo largo del siglo Xx. De ahí la necesidad de rescatar aspectos que aún se encuentran abandonados en archivos públicos o personales y de acceder a las fuentes originales para no caer en los prejuicios y en las omisiones, ello en la vía de reconstruir con mayor objetividad la aún no escrita historia urbana del país.

\section{BIBLIOGRAFÍA}

-Adams, Thomas, Outline of Town and City Planning, Russel Sage Foundation, Filadelfia, 1935.

- Anuario Estadístico de los Estados Unidos Mexicanos 1942, Secretaría de Economía, México, 1948.

-Ashwort, William, The Genesis of Modern British Town Planning, Routledge \& Kegan Paul Ltd, Londres, 1972 (1954).

-Asociación Nacional para la Planificación de la República Mexicana, Revista Planificación, México, 1927-1934.

-Burnham, Daniel y Edward H. Bennett, Plan of Chicago, Princeton Architectural Press, Nueva York, 1993, (ed. facsimilar de la de 1909).
-Choay, Françoise, The Modern City: Planning in the 19 th Century, George Braziller, Nueva York, 1989 (1969).

-Coolidge, Calvin (ed.), Problems of Toun, City and Region, Papers and Discussions at the International City and Regional Planning Conference Planning beld at New York, Remington Co., Baltimore, 1925.

-Collins, George R., The Birth of Modern City Planning, Rizzoli, Nueva York, 1986 (1965).

-Contreras, Carlos, "Informe leído en la International Town, City and Regional Planning Conference en representación de la delegación mexicana", El Arquitecto, núm. v, 1925, México. , "Asociación Nacional para la Planificación de la República Mexicana", Revista Mexicana de Ingeniería y Arquitectura, México, 1926.

- Informe final del XVI Congreso Intcrnacional de Planificación y la Habitación, México, 1939.

-Cuevas, José Luis, "Primeras hiladas para nuestro arte cívico", Anuario 1922-1923, Sociedad de Arquitectos Mexicanos, México, 1923.

-Engels, Federico, "Contribución al problema de la vivienda" en Obras escogidas, Progreso/ Ediciones de Cultura Popular, Moscú, 1979, t. 2 (1872-1873).

- La situación de la clase obrera en Inglaterra, Ediciones de Cultura Popular, México, 1984 (1.845).

-Geddes, Patrick, Cities in Evolution, Howard Fertig, Nueva York, 1968 (ed. facsimilar de la de 1915).

-Howard, Ebenezer, "Ciudades Jardín del mañana" en Carlo Aymonino, Origenes y desarrollo de la ciudad moderna, Gustavo Gili, Barcelona, 1972.

-International Federation for Housing and Town Planning, XIV International Congress for Housing and Town Planning, Londres, 1935.

-Koester, Frank, Modern City Planning and Maintenance, McBride, Nast and Company, Nueva York, 1914. 
-Krueckeberg, Donald A., The American Planer, Bibliographies and Recollections, Methuen, Nueva York, 1983.

-Mortalidad en México, Dirección General de Estadística/Secretaría de la Economía Nacional, México, (s.a.).

-Mumford, Eric, The CIAM Discourse on Urbanism, 1928-1960, MIT Press, Londres, 2002 (1958).

-Nettlefold, J. S., Practical Toun Planning, The St. Catherine Press, Londres, 1914.

-Nolen, John, New Ideals in the Planning of Cities, Towns and Villages, American City Bureau, Nueva York, 1919.

-Olmsted, Frederick L., "Las desventuras de New York" en Sutton, S. B. (comp.), Civilizing American Cities, Writings on City Landscapes, Da Capo Press, Cambridge, 1997.

-Purdom, C. B., "An introductory chapter" en C. B. Purdom (ed.), Town Thenry and Practice, Benn Brothers Limited, Londres, 1921.
-Reps, John W., City and Regional Planning, Department of City and Regional Planning, Cornell University, Nueva York, 2002 en <www.library.cornell.edu/Reps/DOcs/riba.htm>.

-Robinson, Charles M., Modern Civic Art, G. P. Putnam's Sons, Nueva York, 1903.

- The Improvement of Tou'ns and Cities, G. P. Putnam's Sons, Nueva York, 1902 (1901). -Rolland, C. Modesto, El desastre municipal en la república mexicana, Talleres de Publicaciones Rolland, México, 1952 (1921).

-Sánchez Ruiz, Gerardo G., Planificación y urbanismo de la revolución mexicana, UAM-Azcapotzalco/Asamblea Legislativa, México, 2002.

-Sitte, Camillo, "City Planning acording to artistic principles" en George R. Collins, The Birth of Modern City Planning, Rizzoli, Nueva York, 1986 (ed. facsimilar de la de 1889.

-Unwin, Raymond, Toun planning in practice, Princeton Architectural Press, Nueva York, 1994 (ed. facsimilar de la de1909). 